\title{
Comparison of dual antiplatelet therapies after coronary endarterectomy combined with coronary artery bypass grafting: a cohort study
}

Hua Yan ${ }^{\dagger}$, Xieraili Tiemuerniyazi ${ }^{\dagger}$, Yangwu Song, Fei Xu and Wei Feng ${ }^{*}$

\begin{abstract}
Background: Coronary endarterectomy (CE) combined with coronary artery bypass grafting (CABG) can be the only option for complete revascularization in some patients with diffuse coronary artery disease. Unfortunately, CE can cause the lack of endothelium, resulting in increased risk of thrombotic events. Therefore, antithrombotic therapy is very important after surgery. However, there's no consistent protocol exists till now. The aim of this study was to compare the effectiveness and safety of dual antiplatelet therapies (DAPT) including aspirin plus clopidogrel (AC) or ticagrelor (AT) after CE + CABG.
\end{abstract}

Method: A total of 137 continuous patients (mean age 60.0 \pm 9.0 years) underwent CE + CABG from January 2016 to July 2018 in our center, and patients who received dual antiplatelet therapy (DAPT) after surgery $(n=121)$ were included in this study. All of the patients received aspirin $100 \mathrm{mg}$ daily therapy after surgery, and 67 of the patients received extra clopidogrel $75 \mathrm{mg}$ (AC) daily therapy, whereas 54 received extra ticagrelor $90 \mathrm{mg}$ (AT) twice daily. All patients continued aspirin monotherapy after 1 year. Occurrence of ischemic events and bleeding events between two groups were compared. Kaplan-Meier survival was used to compare freedom from major adverse cardiovascular and cerebrovascular events (MACCE) between two groups, and log-rank test was used to confirm statistical difference.

Results: Follow-up was completed by $99.2 \%$, and median follow-up time was $30.0(22.5,35.2)$ months. No operative death was observed, while perioperative myocardial infarction was observed in 2(1.7\%) patients (AC 1.5\% vs. AT 1.9\%, $\mathrm{p}=\mathrm{ns})$. One patient in AC group suffered from cardiac tamponade. During the follow-up period, no death was observed. Ischemic events including nonfatal myocardial infarction, repeat revascularization and ischemic stroke were observed in 6(5.0\%) patients (AC 4.5\% vs. AT 5.6\%, $p=n s$ ). Overt bleeding had occurred in 3(2.5\%) patients (AC 3.0\% vs. AT $1.9 \%, p=n s)$. Kaplan-Meier analysis indicated that MACCE-free survival of the two groups at 3 years was $97.0 \%$ in the AC group versus $94.1 \%$ in the AT group ( $p=n s)$.

Conclusion: In patients undergoing CE + CABG, DAPT therapy can be effective and safe with comparable results between $A C$ and AT therapy in terms of ischemic and bleeding events. Further studies are needed.

Keywords: Coronary endarterectomy, Coronary artery bypass grafting, Dual antiplatelet therapy, Ticagrelor, Clopidogrel

\footnotetext{
* Correspondence: fengwei@fuwai.com

${ }^{\dagger}$ Hua Yan and Xieraili Tiemuerniyazi contributed equally to this work. Department of Cardiovascular Surgery, Fuwai Hospital, National Center for Cardiovascular Diseases, Chinese Academy of Medical Sciences and Peking Union Medical College, Beilishi Road No. 167, Xicheng District, Beijing 100037, China
}

(c) The Author(s). 2020 Open Access This article is licensed under a Creative Commons Attribution 4.0 International License, which permits use, sharing, adaptation, distribution and reproduction in any medium or format, as long as you give appropriate credit to the original author(s) and the source, provide a link to the Creative Commons licence, and indicate if changes were made. The images or other third party material in this article are included in the article's Creative Commons licence, unless indicated otherwise in a credit line to the material. If material is not included in the article's Creative Commons licence and your intended use is not permitted by statutory regulation or exceeds the permitted use, you will need to obtain permission directly from the copyright holder. To view a copy of this licence, visit http://creativecommons.org/licenses/by/4.0/ The Creative Commons Public Domain Dedication waiver (http://creativecommons.org/publicdomain/zero/1.0/) applies to the data made available in this article, unless otherwise stated in a credit line to the data. 


\section{Background}

Coronary endarterectomy (CE) for the treatment of advanced coronary artery disease can be traced back to 1950s [1]. Before long, it became an adjunctive way to coronary artery bypass grafting (CABG) in patients with diffuse coronary artery disease that could not be achieved complete revascularization by CABG or coronary stenting alone. Unfortunately, early results from clinical studies were frustrating [2]. In contrast, studies reported improved clinical outcomes after CE + CABG during last two decades $[3,4]$, and this might be attributed to the improvement in operative techniques and postoperative antithrombotic therapy. However, controversies still exist.

Thrombosis is the major cause of early graft occlusion, and this can lead to poor patient prognosis [5]. Activation of platelet function and even coagulation cascade can occur due to the traumatic stress, blood loss and cardiopulmonary bypass during CABG, and this can last up to more than 1 month [6-8], making antithrombotic treatment particularly important. One of the fatal shortcomings of CE is the loss of intima, which causes direct exposure of sub-endothelial tissue to blood flow, resulting in increased platelet aggregation and activation of coagulation cascade [9]. In other words, there might be more chances of thrombosis after CE + CABG compared to $\mathrm{CABG}$ alone. Therefore, more active postoperative antithrombotic therapy might be required after $\mathrm{CE}+$ CABG.

Clinical guidelines recommend that patients should receive dual antiplatelet therapy (DAPT) for 12 months after CABG [10, 11]. Aspirin plus clopidogrel therapy is the conventional DAPT protocol. However, due to the diversity of drug reactions, sufficient platelet inhibition cannot be achieved in 10 to $63 \%$ of patients with clopidogrel [12, 13]. Ticagrelor, a new P2Y12 receptor antagonist, can achieve stronger and faster platelet inhibition with safe clinical outcomes, and there's no drug reaction diversity when compared with clopidogrel [14-16]. Currently clinical guideline from the European Society of Cardiology recommended both clopidogrel and ticagrelor for DAPT in patients with coronary artery disease [11]. However, there's no consistent antiplatelet therapy protocol after CE + CABG. Several studies existed. Marco Russo and colleagues [17] reported that no significant difference was observed between single antiplatelet therapy with aspirin and DAPT with aspirin plus clopidogrel after CE + CABG, although the study was limited with small sample size. Several studies involved anticoagulation or antiplatelet therapy after CE + CABG [4], but without comparing different protocols. Therefore, more evidence on antithrombotic therapy after $\mathrm{CE}+\mathrm{CABG}$ is needed.
Since it has more rapid onset and offset of action, and there's no drug reaction diversity, ticagrelor might be better than clopidogrel in patients who underwent $\mathrm{CE}+$ CABG. This study was aimed to compare the efficacy and safety outcomes of different DAPT protocols, aspirin plus clopidogrel $(\mathrm{AC})$ versus aspirin plus ticagrelor (AT) therapy, after CE + CABG, as well as to evaluate major adverse cardiovascular and cerebrovascular events (MACCE) free survival of the patients in two groups.

\section{Patients and method}

\section{Patients and study design}

This was a cohort study from our center. A total of 137 continuous patients underwent CE + CABG from January 2016 to July 2018 in our center. One patient died intraoperatively, and 15 patients received single antiplatelet therapy or antiplatelet plus anticoagulation therapy. Therefore, 121 of the patients, who received DAPT only, were finally enrolled. Figure 1 showed the patient enrollment process. Patients were divided into AC and AT groups according to their postoperative DAPT protocol. All of the patients received aspirin 100 mg daily therapy, and patients in the AC group received extra clopidogrel $75 \mathrm{mg}$ daily therapy, while patients in the AT group received extra ticagrelor $90 \mathrm{mg}$ twice daily therapy after surgery. All patients continued single antiplatelet therapy with aspirin after 12 months. The institutional review board at Fuwai Hospital approved the usage of clinical data, and waived individual informed consent for this study.

\section{Operative techniques}

Each patient received $C E$ at least on one site, followed by CABG. The indications for CE included: diffuse coronary artery disease that cannot completely revascularized by CABG alone due to long segment coronary artery occlusion or lumen less than $1 \mathrm{~mm}$, or severe calcification, which was determined by preoperative coronary angiography or intraoperative exploration. Ultimate decision for $\mathrm{CE}$ was made during the operation. $\mathrm{CE}$ was performed by experienced cardiac surgeons by on-pump or off-pump path to achieve complete revascularization before CABG. Closed endarterectomy was preferred in most of the patients, and several patients received patch angioplasty after CE.

\section{Data collection, follow-up and definitions}

Baseline and perioperative characteristics of the patients were collected from reviewing the inpatient medical records, while follow-up was achieved mainly by telephone interview. Primary endpoint was the occurrence of ischemic events defined as the composite of nonfatal myocardial infarction, repeat 
From January 2016 to July 2018, 137 patients underwent CE+CABG

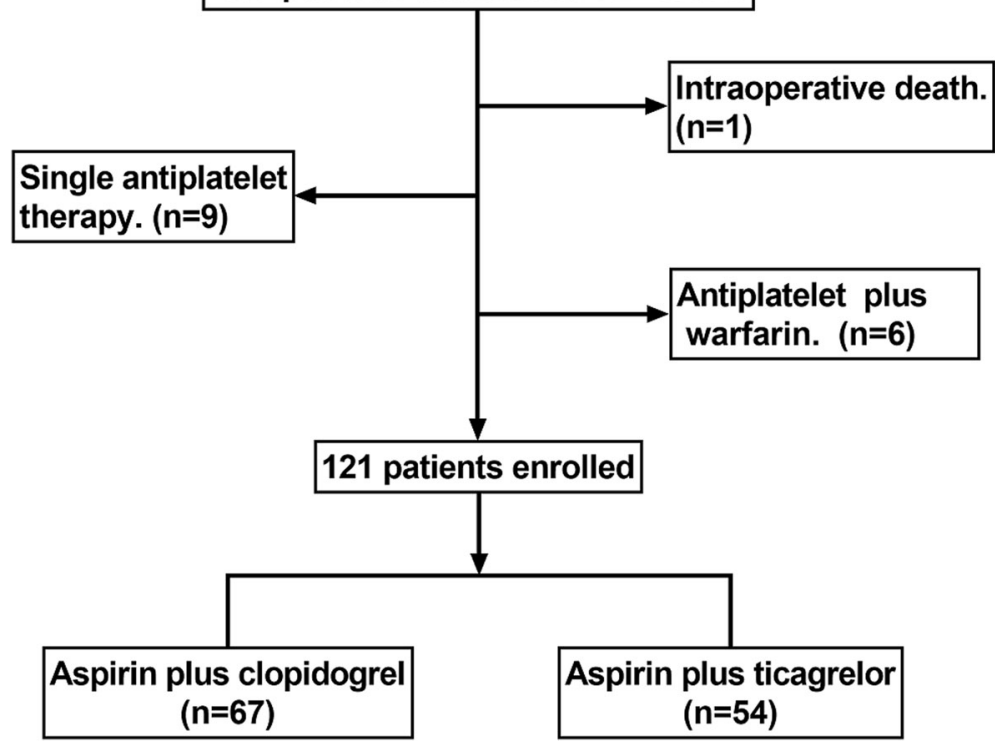

Fig. 1 Flow chart of the patient enrollment process. A total of 137 continuous patients underwent $C E+C A B G$ during the study period. Sixteen patients were excluded for specific reasons showed in the figure, and 121 of the patients enrolled. (CE, coronary endarterectomy; CABG, coronary artery bypass grafting)

revascularization, and nonfatal ischemic stroke. Secondary endpoint was the occurrence of bleeding events, which was defined according to Bleeding Academic Research Consortium Definition for Bleeding definition [18]. Overt bleeding events, which required medical therapy, or cessation of antiplatelet therapy, or threatened the life of patients (type2 to type5), were mainly collected during the follow-up.

Perioperative myocardial infarction was defined according to the fourth universal definition of myocardial infarction [19]. MACCE was defined as the composite of all-cause death, nonfatal myocardial infarction, unplanned repeat coronary revascularization and stroke.

\section{Statistical analysis}

Continuous variables were expressed as mean \pm standard deviation if normally distributed and skewed continuous variables were expressed as the median with the interquartile range. Categorical variables were expressed as frequencies followed by percentages. Normally distributed continuous variables were compared by paired or non-paired Student t-test, and skewed continuous variables were compared using the Wilcoxon's rank-sum test, while categorical variables were compared by Chi-square statistics or Fisher exact test, as appropriate. Cumulative survival and the MACCE-free survival rates were estimated using the
Kaplan-Meier method and compared by log-rank test. Differences with $p$ values of less than 0.05 were considered statistically significant. Statistical analyses were performed using STATA (15.0) (StataCorp, College Station, TX, USA).

\section{Results}

Patient characteristics

Mean age was $60.0 \pm 9.0$ years, and $94(77.7 \%)$ were male. History of prior myocardial infarction differed between AC group and AT group $(p=0.043)$. Comparison of preoperative baseline characteristics between $\mathrm{AC}$ group and AT group were summarized in Table 1 .

Most of the patients underwent off-pump surgery, and all of the patients received internal mammary artery (IMA, mostly left IMA) graft to left anterior descending artery (LAD) in both groups. Most of the patients received CE on LAD (38.8\%) or right coronary artery (RCA, 51.2\%). Several patients also received CE on other sites, including left circumflex artery (7.4\%) and other coronary arteries $(5.8 \%)$ like diagonal branches or intermediate artery. CE sites and other intraoperative characteristics of the patients were comparable between two groups, as shown in Table 2.

\section{Early postoperative results}

Mean ICU stay were $44.0(19,70)$ hours in AC group and $24.5(21.0,69.0)$ hours in AT group $(p=0.365)$. There 
Table 1 Baseline characteristics of the patients

\begin{tabular}{|c|c|c|c|}
\hline Characteristics & $\begin{array}{l}\text { AC group }(n=67) \\
\text { No. }(\%), \text { Mean } \pm \text { SD, Median (range) }\end{array}$ & $\begin{array}{l}\text { AT group }(n=54) \\
\text { No. }(\%), \text { Mean } \pm \text { SD, Median (range) }\end{array}$ & $p$ value \\
\hline Age & $61.4 \pm 8.5$ & $58.2 \pm 9.3$ & 0.055 \\
\hline $\mathrm{BMI}, \mathrm{kg} / \mathrm{m}^{2}$ & $25.5(23.5,27.5)$ & $25.7(24.1,28.0)$ & 0.257 \\
\hline Sex, male & $50(74.6 \%)$ & $44(81.5 \%)$ & 0.368 \\
\hline Prior PCl & $10(14.9 \%)$ & $19(16.7 \%)$ & 0.794 \\
\hline Atrial fibrillation & $2(3.0 \%)$ & $2(3.7 \%)$ & - \\
\hline Hypertension & $45(67.2 \%)$ & $34(64.8 \%)$ & 0.786 \\
\hline Dyslipidemia & $56(83.6 \%)$ & $50(92.6 \%)$ & 0.135 \\
\hline Diabetes mellitus & $30(44.8 \%)$ & $21(38.9 \%)$ & 0.514 \\
\hline Cerebrovascular event & $11(16.4 \%)$ & $11(20.4 \%)$ & 0.575 \\
\hline Chronic kidney failure & $2(3.0 \%)$ & $1(1.9 \%)$ & - \\
\hline Smoking & $39(58.2 \%)$ & $40(74.1 \%)$ & 0.068 \\
\hline Prior cardiac surgery & $1(1.5 \%)$ & $1(1.9 \%)$ & - \\
\hline Prior myocardial infarction & $32(47.8 \%)$ & $16(29.6 \%)$ & $0.043^{\mathrm{a}}$ \\
\hline Triple-vessel disease & $49(73.1 \%)$ & $32(59.3 \%)$ & 0.107 \\
\hline NYHA class III or IV & $29(43.3 \%)$ & $31(57.4 \%)$ & 0.122 \\
\hline Preoperative EF, \% & $62.0(57.0-66.0)$ & $60.0(56.0-65.0)$ & 0.449 \\
\hline
\end{tabular}

$B M I$ body mass index, EF ejection fraction, No. number, NYHA New York Heart Association, $P C l$ percutaneous coronary intervention, $S D$ standard deviation

a Statistically significant

was no operative death. Perioperative myocardial infarction was observed in $2(1.7 \%)$ patients (AC $1.5 \%$ vs. AT $1.9 \%)$, while postoperative new-onset atrial fibrillation was seen in $20(16.5 \%)$ patients (AC $16.4 \%$ vs. AT $16.7 \%$, $p=0.971)$. One patient in AC group suffered from cardiac tamponade at early stage. Early postoperative results were summarized in Table 2.

\section{Follow-up results}

Follow-up was completed by $99.2 \%$, where one patient was lost to contact, and median follow-up time was $30.0(22.5,35.2)$ months. During the follow-up period, no death was observed. Ischemic events were observed in 6(5.0\%) patients without significant difference between two groups (AC $4.5 \%$ vs. AT 5.6\%). Ischemic events

Table 2 Intraoperative and postoperative characteristics

\begin{tabular}{|c|c|c|c|}
\hline Variables & $\begin{array}{l}\text { AC group }(n=67) \\
\text { No. }(\%), \text { Mean } \pm \text { SD, Median (range) }\end{array}$ & $\begin{array}{l}\text { AT group }(n=54) \\
\text { No. }(\%), \text { Mean } \pm \text { SD, Median (range) }\end{array}$ & $p$ value \\
\hline On-pump & $27(40.3 \%)$ & $13(24.1 \%)$ & 0.059 \\
\hline No. of distal anastomosis & $3.5 \pm 0.8$ & $3.4 \pm 0.9$ & 0.391 \\
\hline Usage of IMA to LAD & 67 (100\%) & $54(100 \%)$ & - \\
\hline \multicolumn{4}{|l|}{ Coronary endarterectomy } \\
\hline LAD & $26(38.8 \%)$ & $21(38.9 \%)$ & 0.993 \\
\hline Right coronary artery & $33(49.3 \%)$ & $26(48.2 \%)$ & 0.904 \\
\hline Left circumflex artery & $4(6.0 \%)$ & $5(9.3 \%)$ & 0.493 \\
\hline Other (intermediate, diagonal) & $4(6.0 \%)$ & $5(5.6 \%)$ & - \\
\hline ICU stay & $44.0(19,70)$ & $24.5(21.0,69.0)$ & 0.365 \\
\hline Transfusion & $9(13.4 \%)$ & $3(5.7 \%)$ & 0.150 \\
\hline Postoperative EF, \% & $60.0(58.0,63.0)$ & $60.0(55.0,63.0)$ & 0.330 \\
\hline Cardiac tamponade & $1(1.5 \%)$ & 0 & - \\
\hline Perioperative Ml & $1(1.5 \%)$ & $1(1.9 \%)$ & - \\
\hline New onset atrial fibrillation & $11(16.4 \%)$ & $9(16.7 \%)$ & 0.971 \\
\hline Sternal wound infection & $1(1.5 \%)$ & 0 & - \\
\hline
\end{tabular}

$A C$ aspirin plus clopidogrel, $A T$ aspirin plus ticagrelor, $E F$ ejection fraction, $I C U$ intensive care unit, IMA internal mammary artery, $M I$ myocardial infarction, No. number, $S D$ standard deviation 
included nonfatal myocardial infarction (AC 3.0\% vs. AT $3.7 \%$ ), ischemic stroke (AC $1.5 \%$ vs. AT 0 ), and repeat revascularization (AC 0 vs. AT 1.9\%). Bleeding events were observed in $3(2.5 \%)$ patients (AC $3.0 \%$ vs. AT $1.9 \%$ ), including cardiac tamponade (AC $1.5 \%$ vs. AT 0 ), hemorrhagic stroke (AC 0 vs. AT 1.9\%) and gastrointestinal bleeding (AC $1.5 \%$ vs. AT 0 ), and there was no significant difference between two groups as well. Followup outcomes were summarized in Table 3.

Kaplan-Meier survival function was performed to analyze MACCE-free survival of the patients after CE + CABG. Incidence of MACCE was $4.1 \%$ in total patients during the follow-up, and Fig. 2(A) showed the overall MACCE-free survival. MACCE-free survival of the two groups at 3 years was $97.0 \%$ in the AC group versus 94.1\% in the AT group without difference in the logrank test $(p=0.514)$. Figure 2(B) showed the KaplanMeier survival curve of the two groups.

\section{Discussion}

In this study, we compared the efficacy and safety of two different DAPT protocols, AC versus AT, after CE + CABG. We observed there's no significant difference concerning ischemic and bleeding events, as well as overall MACCE-free survival between the two groups during mid-term follow-up.

Complete revascularization is very important in patients with coronary artery disease, where satisfactory coronary revascularization can be achieved by CABG alone or coronary stenting in most cases. However, it is a challenge for surgeons to achieve complete revascularization in those with diffuse coronary artery disease by conventional techniques. In these cases, $\mathrm{CE}$ had its priority when used adjunctively to CABG. Unlike early study results, researchers reported improved early and late outcomes after CE + CABG in several individual studies during last two decades $[3,4,20]$,

Table 3 Follow-up outcomes

\begin{tabular}{llll}
\hline Variables & $\begin{array}{l}\text { AC group } \\
(n=67)\end{array}$ & $\begin{array}{l}\text { AT group } \\
(n=54)\end{array}$ & $p$ value \\
\hline All-cause death & 0 & 0 & - \\
Ischemic events & $3(4.5 \%)$ & $3(5.6 \%)$ & - \\
$\quad$ Myocardial infarction & $2(3.0 \%)$ & $2(3.7 \%)$ & \\
Ischemic stroke & $1(1.5 \%)$ & 0 & \\
Repeat revascularization & 0 & $1(1.9 \%)$ & \\
Bleeding events & $2(3.0 \%)$ & $1(1.9 \%)$ & - \\
$\quad$ Cardiac tamponade & $1(1.5 \%)$ & 0 & \\
Hemorrhagic stroke & 0 & $1(1.9 \%)$ & \\
Gastrointestinal bleeding & $1(1.5 \%)$ & 0 & 0.514 \\
MACCE & $2(3.0 \%)$ & $3(5.6 \%)$ &
\end{tabular}

$A C$ aspirin plus clopidogrel, $A T$ aspirin plus ticagrelor, MACCE major cardiac and cerebrovascular events, No. number, SD standard deviation although most of the studies were restricted with observational design. Undoubtedly, these results might be attributed to the improvement in operative techniques and postoperative management.

Antithrombotic treatment is one of the most important treatments to improve graft patency and clinical outcomes of patients after coronary revascularization. Loss of coronary intima is one of the disadvantages caused by $\mathrm{CE}$, which in turns leads to the direct exposure of subintimal tissues to blood flow [9] and release of tissue factor. This can be followed by platelet activation and aggregation, resulting in increased risk of thrombosis. Therefore, patients who underwent $\mathrm{CE}+\mathrm{CABG}$ might need more strict antiplatelet therapy compared to CABG alone or stenting.

Clinical guidelines recommended DAPT after CABG alone $[10,11]$, including aspirin plus clopidogrel or ticagrelor. Different from clopidogrel, ticagrelor is a directacting and reversible P2Y12 receptor antagonist with faster and more consistent antiplatelet inhibition effect [21, 22]. Furthermore, both prototype and metabolites of ticagrelor have biological effect [23], which means its effect is stronger and not limited by CYP2C19 gene polymorphism. Several clinical trials also reported stronger platelet inhibition after ticagrelor than clopidogrel [1416]. However, there's no guideline recommendation with respect to antithrombotic therapy after $\mathrm{CE}+\mathrm{CABG}$. There're limited studies that focused on antiplatelet therapy after CE + CABG. In one retrospective study, Russo and colleagues [17] reported compared results in single versus dual antiplatelet therapy after $\mathrm{CE}+\mathrm{CABG}$, but this study was restricted with small sample size. Others involved antithrombotic treatment protocol in their studies, but not focusing on the comparison of antiplatelet therapy [4]. Therefore, more evidence is needed.

Study results indicated good efficacy outcome after aspirin with ticagrelor therapy in patients after CABG [15]. In this study, we observed that composite of ischemic events including nonfatal myocardial infarction, repeat revascularization and ischemic stroke, was comparable between AC group and AT group. This was consistent with the result of a meta-analysis [24], although the study population was from patients with acute coronary syndrome. What cannot be ignored is that sample size of our study was not large enough, and this might have limited the power of test.

In addition to efficacy outcome, safety outcome of antiplatelet drugs is also important. Researchers reported ticagrelor was associated with higher risk of major bleeding when compared with clopidogrel in East Asian patients with acute coronary syndrome in a subgroup analysis of PLATO trial [25]. In this study, bleeding events that required cessation of antiplatelet drugs or 

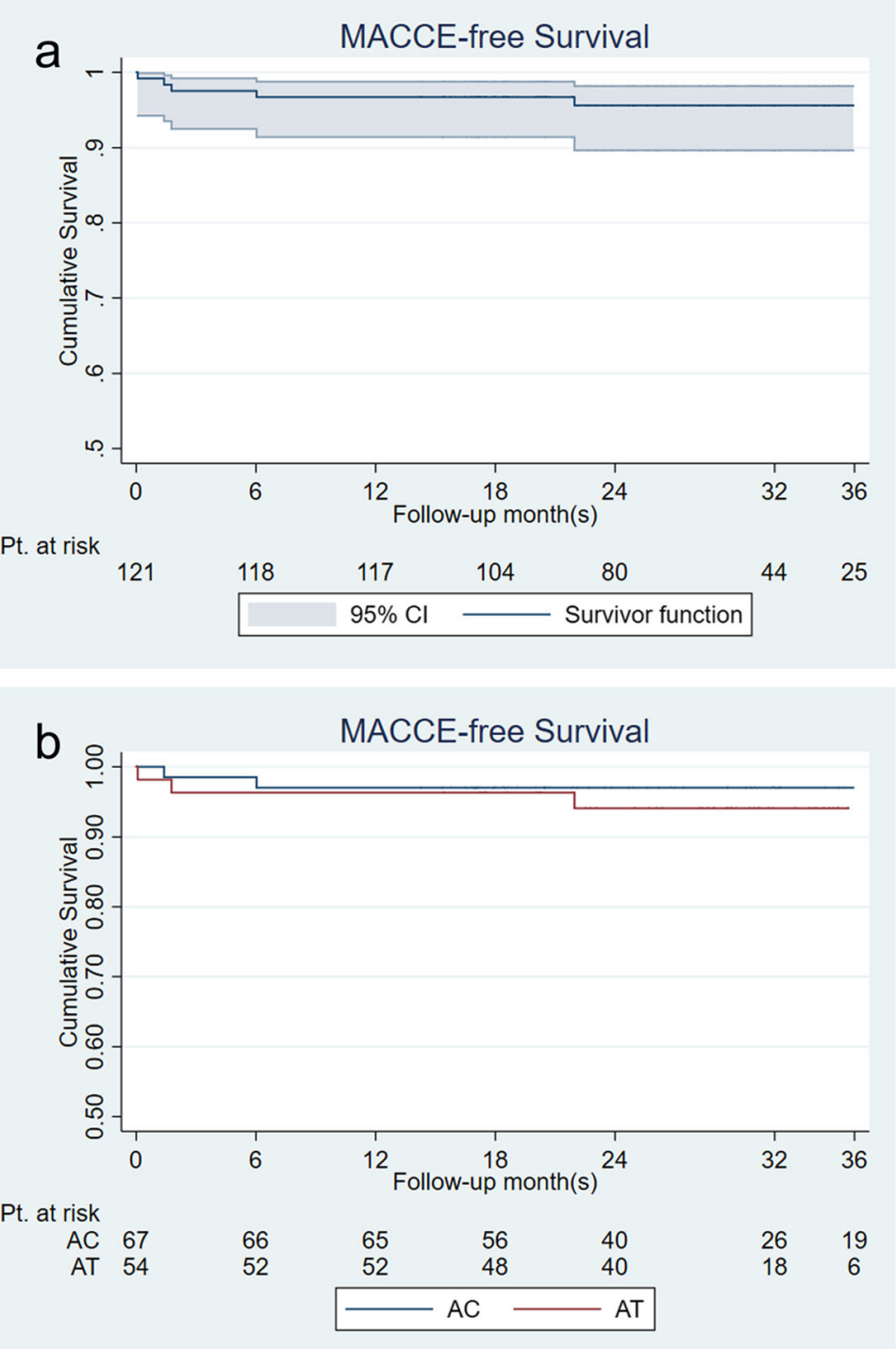

Fig. 2 MACCE-free survival of the patients. a showed the overall MACCE-free survival of all patients; $\mathbf{b}$ showed the comparison of MACCE-free survival between AC group and AT group. (AC, aspirin plus clopidogrel; AT, aspirin plus ticagrelor; Cl, confidence interval; MACCE, major adverse cardiovascular and cerebrovascular events; Pt., patients)

medical intervention, or that was life-threatening, was investigated. Two patients in AC group suffered from bleeding events including cardiac tamponade and gastrointestinal bleeding, while one patient in AT group suffered from hemorrhagic stroke. No difference was observed regarding bleeding events between AC group and AT group. However, it is worth mentioning that minor bleeding events that did not require medical consultation or cessation of drugs, such as subcutaneous petechiae and nasal bleeding, were non considered into account in this study. We also observed that there was no significant difference in the rate of MACCE occurrence between two groups. More large-sample sized studies are needed to confirm these results.
Our study has several limitations. Firstly, this was an observational study, and the bias caused by the study design could not be avoided. Secondly, the sample size was limited, which might reduce the power of tests. Last but by no means least, we collected clinically overt bleeding events, which was defined elsewhere, when comparing the drug safety events between two groups. This might compromise the comparison of secondary endpoint.

\section{Conclusion}

In patients undergoing $\mathrm{CE}+\mathrm{CABG}$, DAPT therapy can be effective and safe with comparable results between $\mathrm{AC}$ and AT therapy in terms of ischemic and bleeding events. Further studies are needed. 


\section{Abbreviations}

AC: aspirin plus clopidogrel; AT: aspirin plus ticagrelor; CABG: coronary artery bypass grafting; CE: coronary endarterectomy; DAPT: dual antiplatelet therapy; IMA: internal mammary artery; LAD: left anterior descending artery; MACCE: major adverse cardiovascular and cerebrovascular events; RCA: right coronary artery

\section{Acknowledgements}

Not applicable.

\section{Authors' contributions}

HY \& XT designed and carried out the study, collected the data, completed the follow-up of the patients, and finished the writing up of the original draft together, and contributed equally to the study. YS participated in the collection and analysis of the data. FX provided active help, guidance and valuable suggestions regarding study design, and reviewed and provided suggestions on editing. WF participated in study design, planning, and carrying out, provided expert guidance to analysis and writing up, and administered and supervised this work. The author(s) read and approved the final manuscript.

\section{Funding}

This work was supported by the National Key Research and Development. Program (2018YFC1311201) from the Ministry of Science and Technology of the People's Republic of China on the design of the study, collection and follow-up of the patients, and as well as on data analysis.

\section{Availability of data and materials}

The data used to support the findings of this study are available from the corresponding author upon request.

\section{Ethics approval and consent to participate}

The institutional review board at Fuwai Hospital approved the usage of clinical data, and waived individual informed consent for this study.

\section{Consent for publication}

Not applicable.

\section{Competing interests}

The authors declare that they have no competing interests.

Received: 25 April 2020 Accepted: 22 June 2020

Published online: 29 June 2020

\section{References}

1. Bailey CP, May A, Lemmon WM. Survival after coronary endarterectomy in man. J Am Med Assoc. 1957;164(6):641-6.

2. Gale AW, Chang VP, Shanahan MX, Windsor HM. Right coronary endarterectomy: a procedure with increased risk of perioperative infarction. Aust N Z J Surg. 1977;47(4):515-8.

3. Qiu Z, Auchoybur ML, Xu Y, Jiang $Y$, Wang $L, X u M$, et al. The midterm results of coronary endarterectomy in patients with diffuse coronary artery disease. J Cardiothorac Surg. 2018;13(1):90.

4. Nishigawa K, Fukui T, Yamazaki M, Takanashi S. Ten-year experience of coronary Endarterectomy for the diffusely diseased left anterior descending artery. Ann Thorac Surg. 2017;103(3):710-6.

5. Motwani JG, Topol EJ. Aortocoronary saphenous vein graft disease: pathogenesis, predisposition, and prevention. Circulation. 1998;97(9):916-31.

6. Parolari A, Colli S, Mussoni L, Eligini S, Naliato M, Wang X, et al. Coagulation and fibrinolytic markers in a two-month follow-up of coronary bypass surgery. J Thorac Cardiovasc Surg. 2003;125(2):336-43.

7. Parolari A, Mussoni L, Frigerio M, Naliato M, Alamanni F, Galanti A et al. Increased prothrombotic state lasting as long as one month after on-pump and off-pump coronary surgery. J Thorac Cardiovasc Surg. 2005;130(2):303-8

8. Vallely MP, Bannon PG, Bayfield MS, Hughes CF, Kritharides L. Quantitative and temporal differences in coagulation, fibrinolysis and platelet activation after on-pump and off-pump coronary artery bypass surgery. Heart Lung Circ. 2009;18(2):123-30

9. Papakonstantinou NA, Baikoussis NG, Apostolakis E. Coronary endarterectomy: new flavors from old recipes. J Cardiol. 2014;63(6):397-401.
10. Levine GN, Bates ER, Bittl JA, Brindis RG, Finn SD, Fleisher LA, et al. 2016 ACC/AHA guideline focused update on duration of dual antiplatelet therapy in patients with coronary artery disease: a report of the American College of Cardiology/American Heart Association task force on clinical practice guidelines. J Am Coll Cardiol. 2016;68(10):1082-115.

11. Valgimigli M, Bueno H, Byrne RA, Collet JP, Costa F, Jeppsson A, et al. 2017 ESC focused update on dual antiplatelet therapy in coronary artery disease developed in collaboration with EACTS: the task force for dual antiplatelet therapy in coronary artery disease of the European Society of Cardiology (ESC) and of the European Association for Cardio-Thoracic Surgery (EACTS). Eur Heart J. 2018:39(3):213-60.

12. Serebruany VL, Steinhubl SR, Berger PB, Malinin Al, Bhatt DL, Topol EJ. Variability in platelet responsiveness to clopidogrel among 544 individuals. J Am Coll Cardiol. 2005;45(2):246-51.

13. Heestermans AA, van Werkum JW, Schömig E, ten Berg JM, Taubert D. Clopidogrel resistance caused by a failure to metabolize clopidogrel into its metabolites. J Thromb Haemost. 2006;4(5):1143-5.

14. Gurbel PA, Bliden KP, Butler K, Tantry US, Gesheff T, Wei C, et al. Randomized double-blind assessment of the ONSET and OFFSET of the antiplatelet effects of ticagrelor versus clopidogrel in patients with stable coronary artery disease: the ONSET/OFFSET study. Circulation. 2009;120(25): 2577-85

15. Brilakis ES, Held C, Meier B, Cools F, Claeys MJ, Cornel JH, et al. Effect of ticagrelor on the outcomes of patients with prior coronary artery bypass graft surgery: insights from the PLATelet inhibition and patient outcomes (PLATO) trial. Am Heart J. 2013:166(3):474-80.

16. Gurbel PA, Bliden KP, Butler K, Antonino MJ, Wei C, Teng R, et al. Response to ticagrelor in clopidogrel nonresponders and responders and effect of switching therapies: the RESPOND study. Circulation. 2010;121(10):1188-99.

17. Russo M, Nardi P, Saitto G, Bovio E, Pellegrino A, Scafuri A, et al. Single versus double antiplatelet therapy in patients undergoing coronary artery bypass grafting with coronary endarterectomy: mid-term results and clinical implications. Interact Cardiovasc Thorac Surg. 2017:24(2):203-8.

18. Mehran R, Rao SV, Bhatt DL, Gibson CM, Caixeta A, Eikelboom J, et al. Standardized bleeding definitions for cardiovascular clinical trials: a consensus report from the bleeding academic research consortium Circulation. 2011:123(23):2736-47.

19. Thygesen K, Alpert JS, Jaffe AS, Chaitman BR, Bax JJ, Morrow DA, et al. Fourth universal definition of myocardial infarction (2018). J Am Coll Cardiol. 2018;72(18):2231-64

20. Janiec M, Ragnarsson S, Nozohoor S. Long-term outcome after coronary endarterectomy adjunct to coronary artery bypass grafting. Interact Cardiovasc Thorac Surg. 2019;29(1):22-7.

21. Goel D. Ticagrelor: the first approved reversible oral antiplatelet agent. Int J Appl Basic Med Res. 2013;3(1):19-21.

22. Storey RF, Husted S, Harrington RA, Heptinstall S, Wilcox RG, Peters G, et al. Inhibition of platelet aggregation by AZD6140, a reversible oral P2Y12 receptor antagonist, compared with clopidogrel in patients with acute coronary syndromes. J Am Coll Cardiol. 2007;50(19):1852-6.

23. Capodanno D, Dharmashankar K, Angiolillo DJ. Mechanism of action and clinical development of ticagrelor, a novel platelet ADP P2Y12 receptor antagonist. Expert Rev Cardiovasc Ther. 2010;8(2):151-8.

24. Guan W, Lu H, Yang K. Choosing between ticagrelor and clopidogrel following percutaneous coronary intervention: a systematic review and meta-analysis (2007-2017). Medicine (Baltimore). 2018;97(43):e12978.

25. Misumida N, Aoi S, Kim SM, Ziada KM, Abdel-Latif A. Ticagrelor versus clopidogrel in east Asian patients with acute coronary syndrome: systematic review and meta-analysis. Cardiovasc Revasc Med. 2018;19(6):689-94.

\section{Publisher's Note}

Springer Nature remains neutral with regard to jurisdictional claims in published maps and institutional affiliations. 